\title{
Effect of network mesh size on the thermo-mechanical properties of epoxy nanocomposites with the heavier homologue of POSS, the inorganic butylstannoxane cages
}

\author{
Krzysztof Rodzeń ${ }^{\mathrm{a}}$, Adam Strachota ${ }^{\mathrm{a}, *}$, François Ribot ${ }^{\mathrm{b}, \mathrm{c}, \mathrm{d}}$, Miroslav Šlouf ${ }^{\mathrm{a}}$ \\ ${ }^{a}$ Institute of Macromolecular Chemistry v.v.i., Academy of Sciences of the Czech Republic, Heyrovskeho nam. 2, CZ-162 00 Praha, Czech Republic \\ ${ }^{\mathrm{b}}$ Sorbonne Universités, UPMC Univ Paris 06, UMR 7574, Chimie de la Matière Condensée de Paris, F-75005 Paris, France \\ ${ }^{\mathrm{c}}$ CNRS, UMR 7574, Chimie de la Matière Condensée de Paris, F-75005 Paris, France \\ ${ }^{\mathrm{d}}$ Collège de France, UMR 7574, Chimie de la Matière Condensée de Paris, F-75005 Paris, France
}

\begin{abstract}
A novel tin-based POSS analogue, butylstannoxane dodecamer, was incorporated into epoxy networks with strongly different mesh sizes in comparison to the nanofiller dimensions. The stannoxane cage is especially attractive due to its anti-oxidative effect, which is based on oxidative crosslinking reactions. It can also cause additional reinforcement via nanofiller units' oligomerization. The strongest mechanical reinforcement was observed in nanocomposites with a network mesh width close, but somewhat larger, than was the stannoxane cage size. In the narrow-mesh-matrix, the large rigid nanofiller causes a plastification, due to sterical impossibility of formation of some crosslinks around the filler units. The strongest anti-oxidative effect of the stannoxane was observed in the matrix with the widest mesh, which had the longest polypropylene oxide chains, and hence the largest number of sites potentially reacting with the stannoxane in oxidative crosslinking reactions. The homogeneity of the prepared nanocomposites was evaluated by TEM.
\end{abstract}

\section{Introduction}

A tin-based heavy analogue (Scheme 1a) of the wellknown polyhedral oligomeric silsesquioxane (POSS) nano-building block (Scheme 1b) was incorporated into epoxy nanocomposites as chemically reactive filler with a strong anti-oxidative effect, which was investigated and optimized in this work.

A general advantage of nano-composites in comparison with conventional ones consists in the small size of filler, which mostly makes possible the use of the same processing techniques for the nanocomposites, like for the neat matrix [1-3]. In case that the filler is sufficiently small in

\footnotetext{
* Corresponding author. Tel.: +420 296809 384; fax: +420 296809410 .

E-mail address: strachota@imc.cas.cz (A. Strachota).
}

comparison to visible light wavelength, optical transparency is also preserved. Additionally, the intrinsic properties of the selected nanofiller can provide specific chemical [4-6], optical [7-9], electrical [10,11], magnetic [12,13], or gas barrier [14-18] properties to the final nanocomposites. A marked mechanical reinforcement can be achieved with small nanofiller amounts, due to their high specific surface [19-23].

In their recent work, the authors investigated epoxynanocomposites reinforced by chemically bonded inorganic POSS cages [24-26] and demonstrated the key importance of POSS-POSS interactions for the mechanical reinforcement in these nanocomposites. The organic substituents attached onto the POSS surface were shown to control the filler-filler interaction [25]. The physical crosslinking and the topological constraint to elastic chain 
(a)

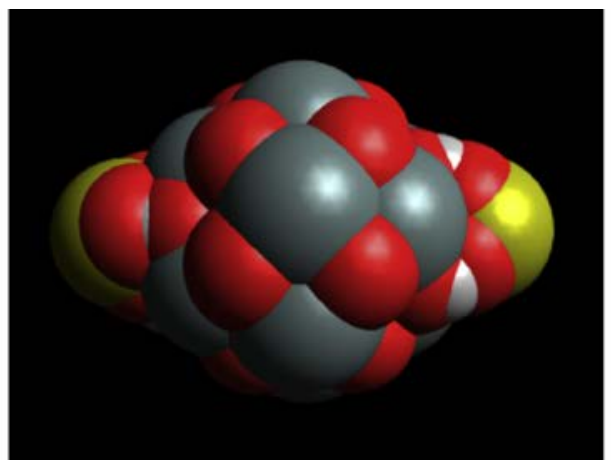

(b)

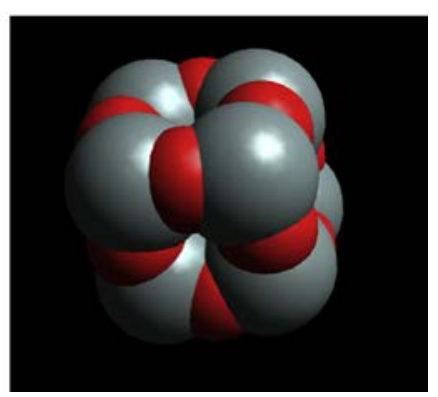

Scheme 1. (a) The inorganic $\mathrm{Sn}_{12} \mathrm{O}_{14}(\mathrm{OH})_{6}\left(\mathrm{O}_{3} \mathrm{~S}\right)_{2}$ core of the ellipsoid butylstannoxane dodecamer nano-building block (see Scheme 4) which was used in this work; (b) polyhedral oligomeric silsesquioxane (POSS) nanobuilding block: inorganic $\mathrm{Si}_{8} \mathrm{O}_{12}$ core sized approximately 0.5 nm.

motion caused by hard domains of aggregated (matrixbonded) POSS nanofiller was demonstrated [26,27] to contribute to mechanical reinforcement as well as to increased thermal stability.

The tin-based "super POSS" (oligomeric butylstannoxane) shown in Scheme 1a is of interest due to its larger and heavier inorganic core, and also to its higher chemical reactivity in comparison to POSS, which is given by the stronger metallic character of Sn, and by the weaker Sn$\mathrm{C}$ bond strength. The butyl stannoxane dodecamer cage has a $1.2 \mathrm{~nm}$ long and $0.7 \mathrm{~nm}$ wide ellipsoid (polyhedral) inorganic core, which is covered by the butyl substituents, thereby achieving the overall dimensions of $2.3 \times 4.7 \mathrm{~nm}$ [28], while the quasi-spherical POSS has the dimensions of $0.5 \mathrm{~nm}$ (core) and $1.5 \mathrm{~nm}$ core with typical substituents (Scheme 1b). The attachment of two functional (or eventually inert) substituents by ionic bonds in axial positions of the stannoxane ellipsoid is a unique feature of this nanofiller, which makes possible its easy incorporation into polymer backbones and other linear structures [37,38]. In contrast to this, POSS can be easily obtained either monofunctional or octa-functional. Ionic dissociation of the stannoxane axial substituents, anion exchange reactions as well as supramolecular assembly under specific conditions were reported by Ribot et al. $[29,30]$ and contribute to this nanofiller's unusual chemistry. A specific property is also the rearrangement into larger structures at elevated temperature, as reported by Ribot et al. [28].

Well-defined oligomeric alkylstannoxane cages similar to the one shown in Scheme 1a were first prepared in 1989 (POSS already in 1946) by Puff and Reuter [31], followed by Dakternieks et al. [32]. In some analogy to siloxane chemistry, a large family of stannoxane compounds exists [33-35], including structures like linear, branched and ladder polymers, networks, drums and cages of different sizes. In 2000, Ribot [28,36], one of the authors of this work, developed a new, high-yield synthesis route to the butyl stannoxane dodecamer, thus making possible its synthesis on a large scale, and its thorough characterization.

Only a few pioneering works were published up to date about polymeric materials containing stannoxane cages: Ribot et al. reported the preparation of carboxylate-based self-assembled organic-inorganic hybrids with stannoxane [37,38] and of a methacrylate-stannoxane copolymer [39]. Recently, also the authors of this work turned their interest to the heavier tin-based POSS analogue and incorporated oligomeric butylstannoxane for the first time into epoxy resins [40,41]. The stannoxane nanocomposites were shown to display some similar behavior like the previously studied epoxy-POSS systems, e.g. mechanical matrix reinforcement via the interaction of the inorganic cages (physical crosslinking), but they also displayed new properties, like the anti-oxidative action of the nanofiller, which was found to strongly stabilize the matrix via oxidative crosslinking reactions [40] (Scheme 2), even at very low concentrations [41]. Another unusual reaction of the stannoxane nanofiller is its oligomerization to larger units $[40,41]$ (Scheme 3), which under suitable conditions can generate an additional reinforcement of the nanocomposite [41].

The aim of this work was the incorporation of the linearly bonding amino-functional "Sn2" nanofiller (Scheme 4),

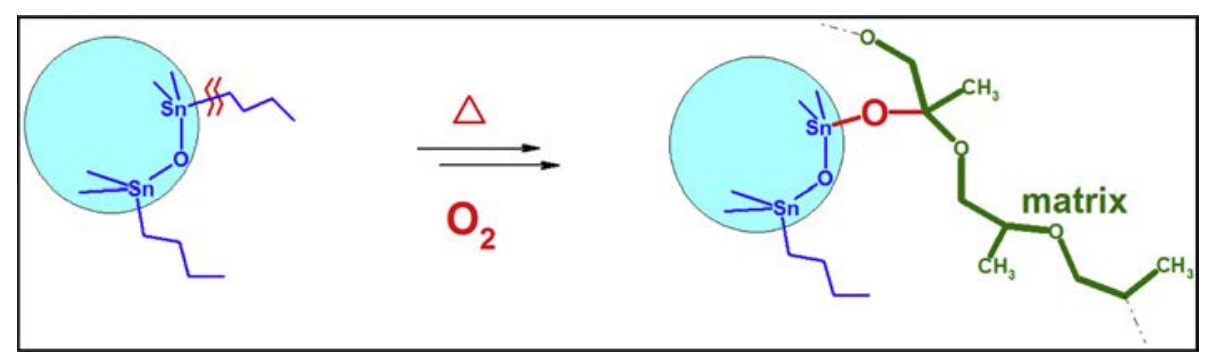

Scheme 2. Oxidative crosslinking reactions of the stannoxane nano-building blocks with the matrix, as proven by ${ }^{1} \mathrm{H}$ NMR experiments in previous work [40], which proceed via de-butylation of the stannoxane cage. 

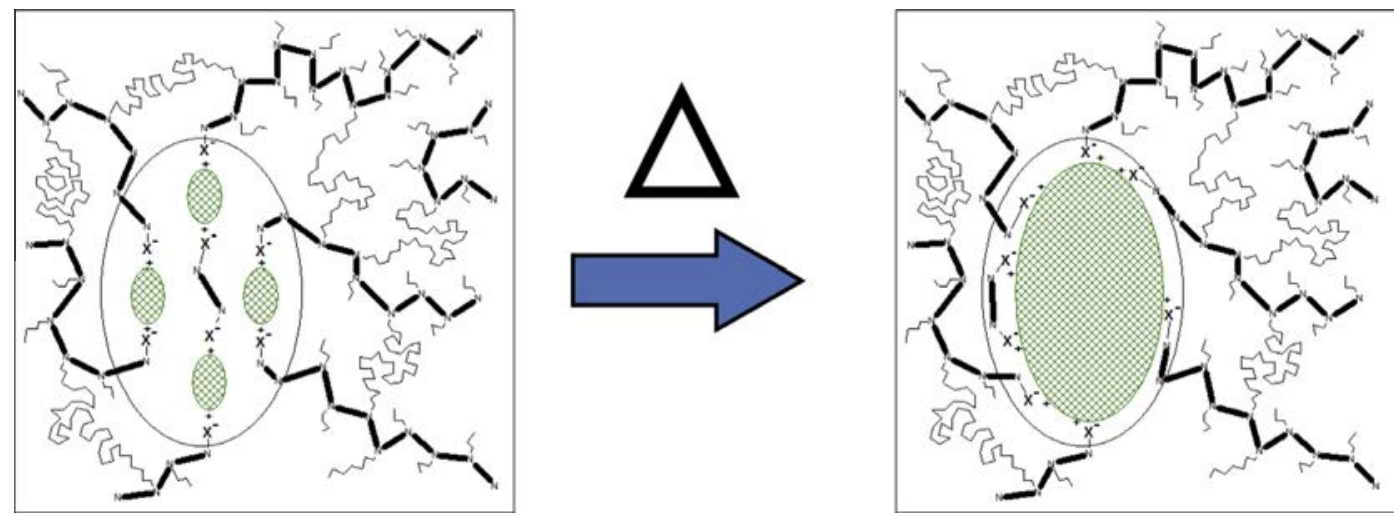

Scheme 3. Stannoxane oligomerization at elevated temperatures.

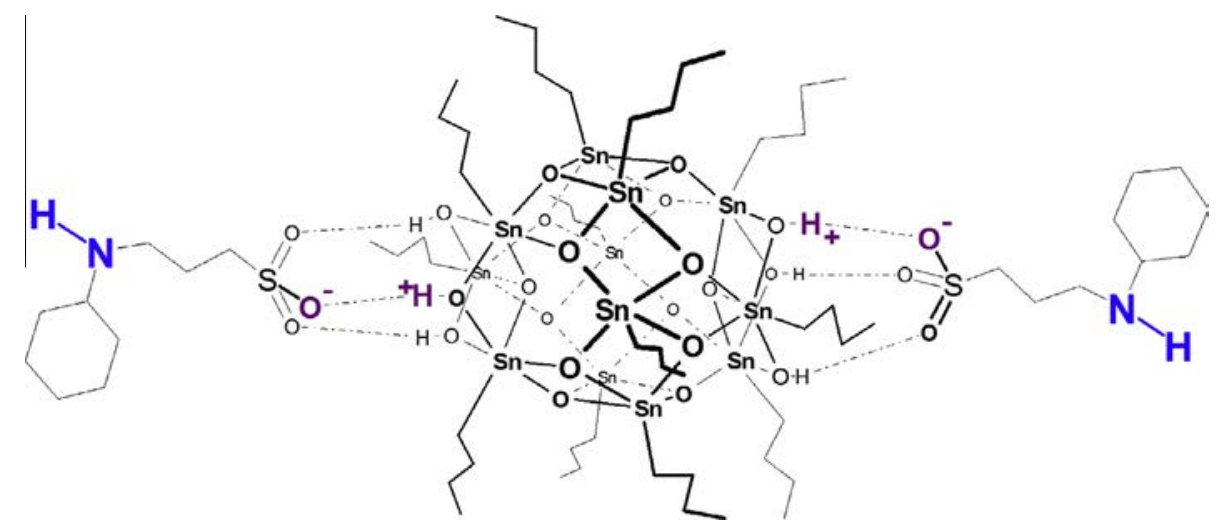

Scheme 4. Linearly bonding amino-functional butylstannoxane dodecamer cage "Sn2" used in this work: $\left[\left(\mathrm{nC}_{4} \mathrm{H}_{9}-\mathrm{Sn}_{12}(\mathrm{O})_{14}(\mathrm{OH})_{6}\right]\left[\mathrm{O}_{3} \mathrm{~S}-(\mathrm{CH})_{3}-\mathrm{NH}_{-}\right.\right.$ $\left.\mathrm{C}_{6} \mathrm{H}_{11}\right]_{2}$.

which was previously shown to display an especially strong anti-oxidative effect [41], into epoxy thermosets with different mesh width of their network structure. The tested matrices ranged from an elastomeric one, with the mesh much wider than the nanofiller size, to a hard glassy matrix with a mesh width significantly smaller than the Sn2 cage. The mechanical reinforcement by the rigid inorganic Sn2 cages, the additional strengthening achievable by $\mathrm{Sn} 2$ oligomerization, and the anti-oxidative stabilizing effect of Sn2 were evaluated and compared for the different matrix mesh sizes (see Scheme 8).

\section{Experimental}

\subsection{Materials}

The poly(oxypropylene) diamines "Jeffamine D2000" ( molecular weight $=1968 \mathrm{~g} / \mathrm{mol})$, "Jeffamine D400" (molecular weight $=432 \mathrm{~g} / \mathrm{mol}$ ) and "Jeffamine D230" (molecular weight $=230 \mathrm{~g} / \mathrm{mol}$ ), as well as the epoxide Diglycidyl ether of Bisphenol A ("DGEBA", 99.7\% pure) were purchased from Sigma-Aldrich and used as obtained.

The amino-H-bifunctional Stannoxane cage "Sn2" was synthesized as described in the previous work of one of the authors $[28,36]$. Butyl tin oxide hydroxide hydrate, $\mathrm{BuSnO}(\mathrm{OH}) \cdot \mathrm{H}_{2} \mathrm{O}$, was used as starting material and reacted with toluenesulfonic acid to yield the non-functional cage "Sn_0" with toluenesulfonate axial groups. The stannoxane toluenesulfonate was converted into the dihydroxide in an ion exchange reaction using tetramethylammonium hydroxide. The dihydroxide was subsequently neutralized with $\mathrm{N}$-cyclohexyl-3-aminopropanesulfonic acid, thus yielding "Sn2". All the above mentioned chemicals were purchased from Sigma-Aldrich and used as obtained.

\subsection{Nanocomposite synthesis (see Scheme 5)}

\subsubsection{Preparation of normally cured samples}

The desired amounts of molten and supercooled epoxide DGEBA, of the liquid Jeffamine D (D2000 or D400 or D230), and of a $50 \mathrm{wt} \%$ stannoxane cage solution in toluene were mixed, the homogeneous clear reaction mixture was heated to $120^{\circ} \mathrm{C}$ and stirred in an open vessel till gelation (typically ca. $40 \mathrm{~min}$ ). Subsequently, the remaining solvent was removed by briefly applying vacuum at $120^{\circ} \mathrm{C}$. The plastic (and also clear, homogeneous) early post-gel mixture was pressed into a mold $(30 \times 10 \times 1 \mathrm{~mm})$ and cured at $120^{\circ} \mathrm{C}$ for 3 days. No air was entering the mold during 


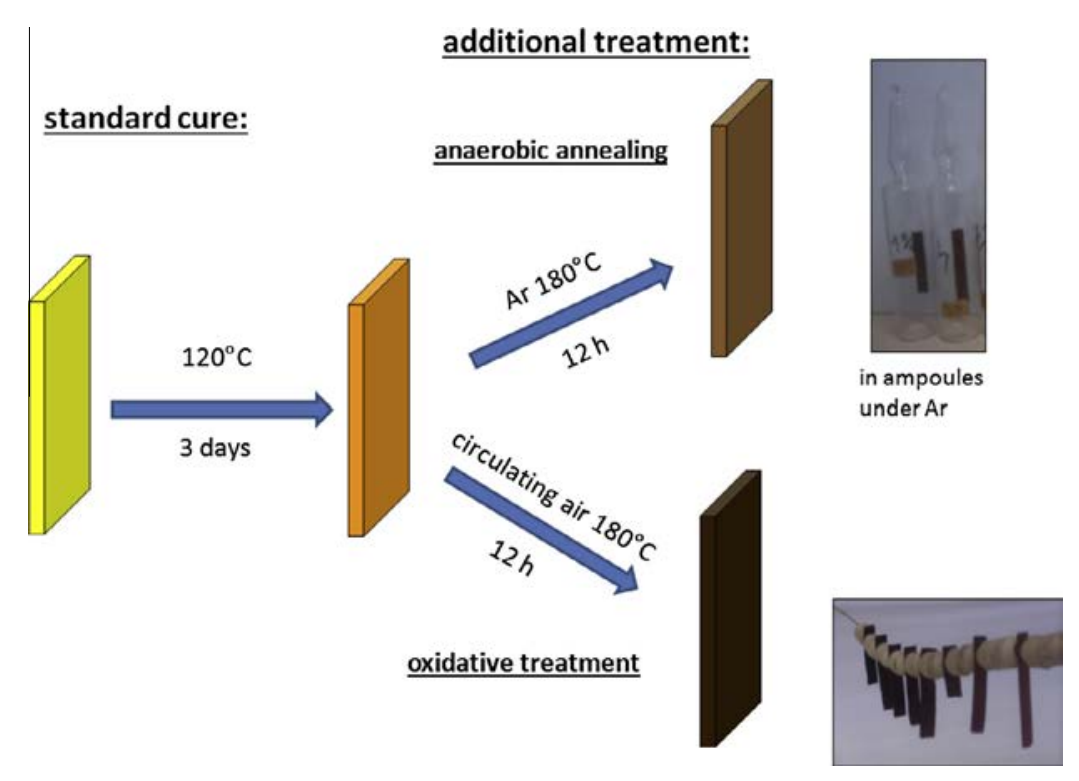

Scheme 5. Samples preparation: normal cure, annealing under Ar and oxidative treatment.
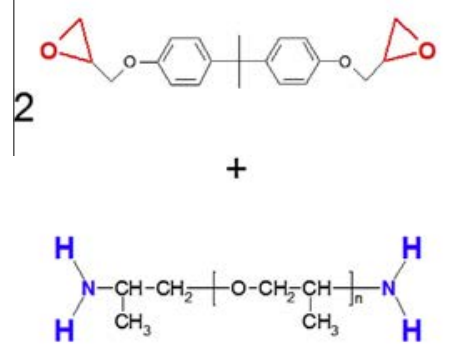

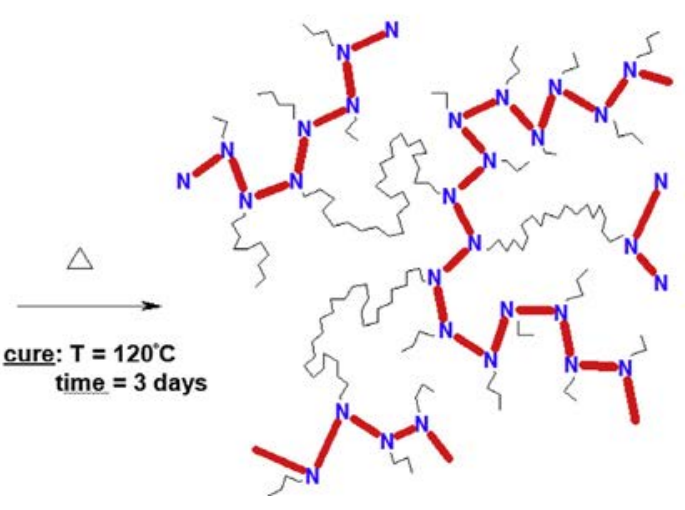

Scheme 6. The studied matrices and their synthesis.
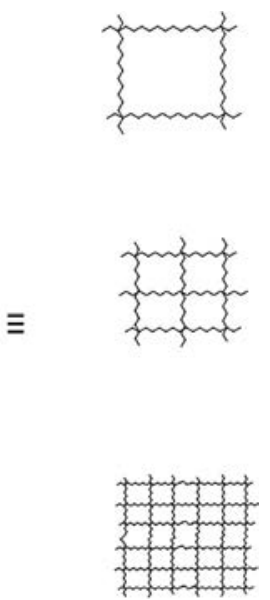

the process. Only stoichiometric formulations were prepared, the stoichiometry being defined by the molar ratio of functional groups $r=($ amino- $H) /($ epoxy $)=1$. The formulations were calculated by replacing $10,4.8$ and 3.9 amino-H-protons of the matrix' amino component D2000, D400 and D230, respectively, by the amino-H protons of $\mathrm{Sn} 2$. In this way, nanocomposites containing always $20 \mathrm{wt} \%$ Sn2 were obtained.

\subsubsection{Nanofiller oligomerization via additional annealing under argon}

Annealing (after normal cure) of the prepared nanocomposites was performed by heating the samples to $180^{\circ} \mathrm{C}$ under argon atmosphere for $12 \mathrm{~h}$.
Oxidative treatment of the prepared nanocomposites was performed (after normal cure) by heating the samples at $180{ }^{\circ} \mathrm{C}$ in air for $12 \mathrm{~h}$, using a forced circulation oven. The sample size was always identical: $30 \mathrm{~mm}$ height, $10 \mathrm{~mm}$ width, and $1 \mathrm{~mm}$ thickness. A small hole was drilled in the top of each sample, and the samples were hanging on a thin wire in the central part of the circulation oven, in order to ensure an optimal access of the circulating air.

\subsection{Characterization of the nanocomposites}

\subsubsection{TEM}

Transmission electron microscopy (TEM) was performed using the Tecnai G2 Spirit Twin 12 microscope (FEI, Czech Republic) after the thin samples (approximately 

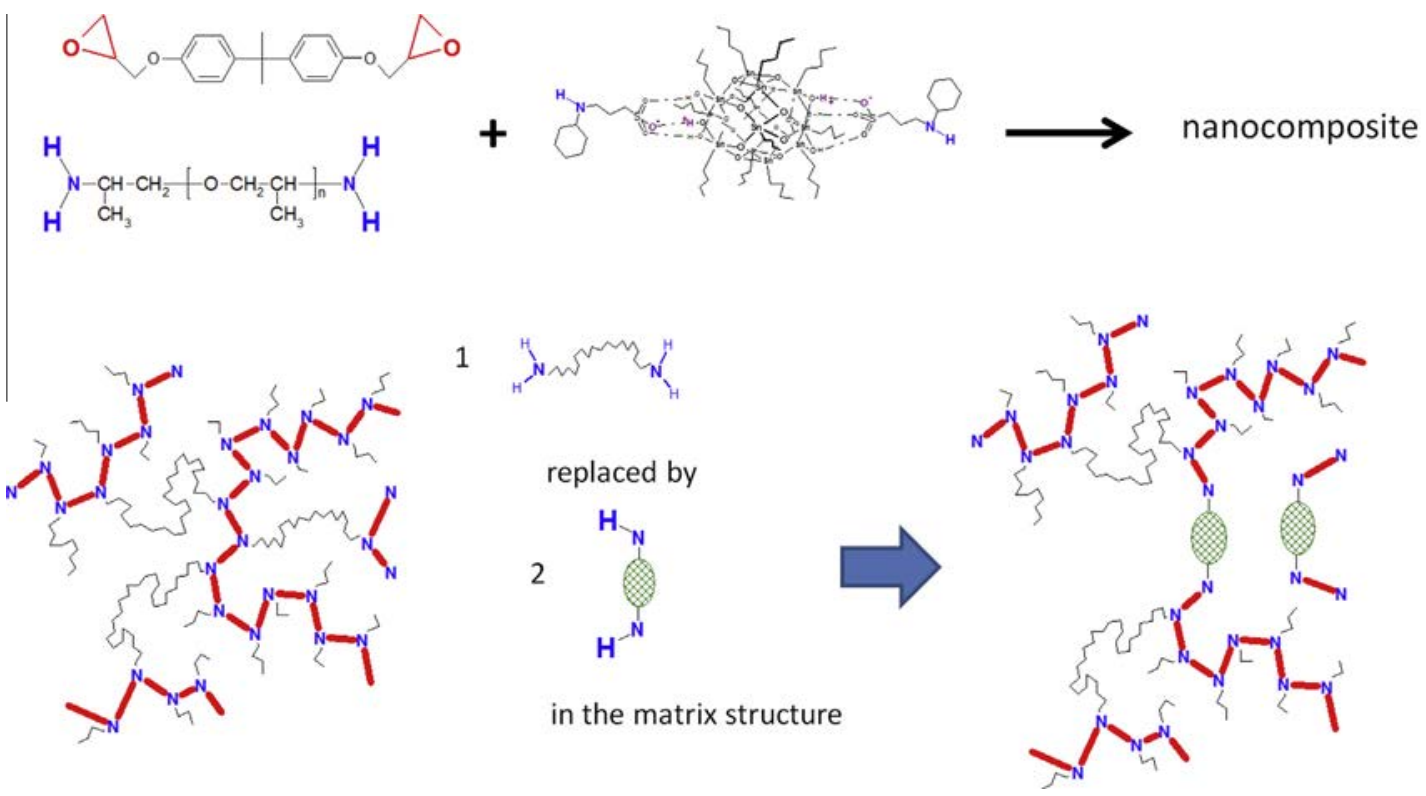

Scheme 7. Synthesis of the studied nanocomposites and their idealized chemical structure.
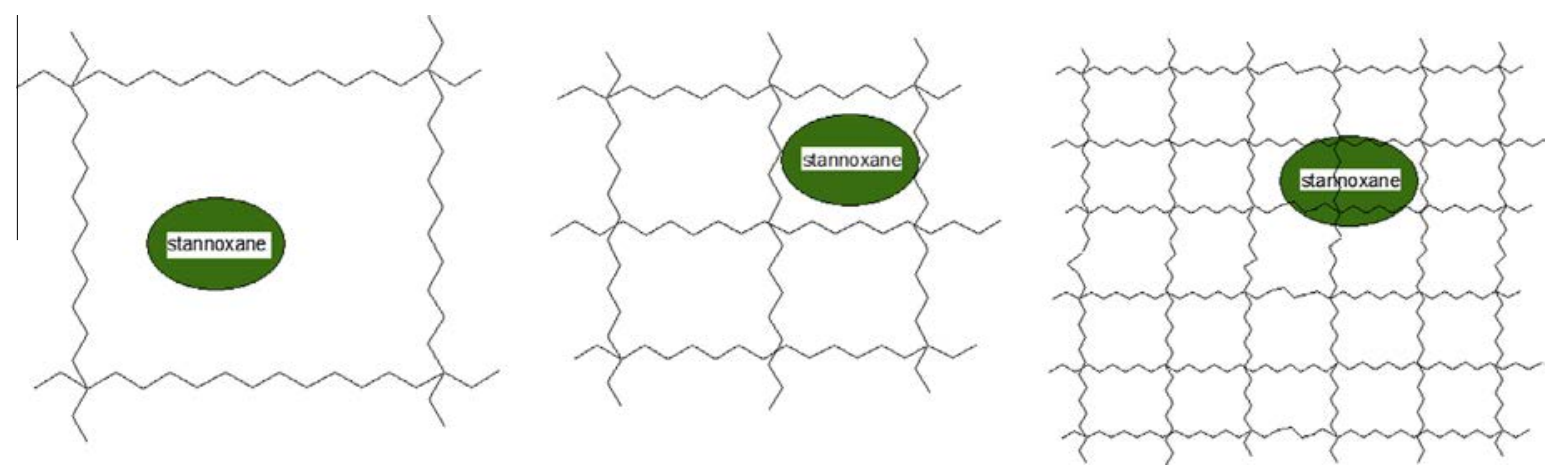

Scheme 8. Relative size of the Sn2 nanofiller in comparison to the mesh of the matrices DGEBA-D2000, DGEBA-D400 and DGEBA-D230.

$60 \mathrm{~nm}$ thick) were prepared by an ultramicrotome (Ultracut UCT, Leica, Germany) under cryogenic conditions (the sample and knife temperatures were -80 and $-50{ }^{\circ} \mathrm{C}$, respectively). The ultrathin sections were transferred to a microscopic grid and observed in the bright field mode at the acceleration voltage of $120 \mathrm{kV}$.

\subsubsection{DMTA}

Dynamic mechanical properties of the nanocomposite products were tested with rectangular platelet samples, using an ARES G2 apparatus from TA Instruments. An oscillatory shear deformation $(0.1 \%)$ at the constant frequency of $1 \mathrm{~Hz}$ and at the heating rate of $3{ }^{\circ} \mathrm{C} / \mathrm{min}$ was applied, and the temperature dependences of the storage shear modulus and of the loss factor ( $G^{\prime}$ and $\tan ($ delta), respectively) were recorded. The temperature range was typically from -100 to $+120^{\circ} \mathrm{C}$, or -100 to $+180^{\circ} \mathrm{C}$ in case of nanocomposites which were annealed or oxidized. The geometry of the deformed area of all the tested samples was the same: $30 \mathrm{~mm}$ height, $10 \mathrm{~mm}$ width, and $1 \mathrm{~mm}$ thickness.

\section{Results and discussion}

\subsection{Nanocomposite synthesis}

The epoxy resins, which were used as matrices for nanocomposites in this work, were prepared according to Scheme 6 . They are based on diglycidylether of bisphenol A (DGEBA) and poly(oxypropylene)- $\alpha, \omega$-diamines ("D2000", $\mathrm{MW}=1968 \mathrm{~g} / \mathrm{mol}, 34$ repeat units; "D400", $\mathrm{MW}=432$ $\mathrm{g} / \mathrm{mol}, 7$ repeat units; and "D230”, $\mathrm{MW}=230 \mathrm{~g} / \mathrm{mol}, 3.5$ repeat units).

The polypropyleneoxide diamines play the role of elastic chains in the matrices. Due to their different lengths, the matrices range from the elastomeric DGEBA-D2000 to the hard glassy DGEBA-D230. The structure of the matrices (see Scheme 6) consists of rather rigid chains made of 


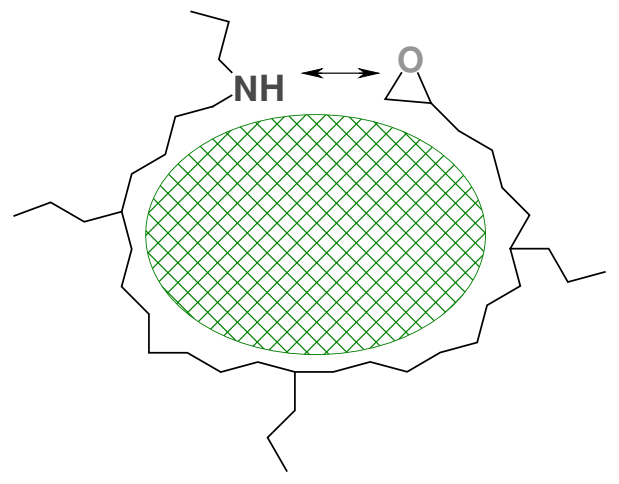

Scheme 9. Schematic representation of the sterical hindrance by $\mathrm{Sn} 2$ of the formation of the typical loops in a narrow network mesh, e.g. DGEBAD230.

aromatic DGEBA units and $\mathrm{N}$-atoms from Jeffamine $\mathrm{D}$, which are interconnected by the elastic polypropylene oxide chains (Jeffamine D) of different length.

The nanocomposites of the above described epoxy resins with the nanofiller "Sn2" (see Scheme 4) were prepared via reaction blending according to Scheme 7: Sn2 cages
(amino-H-bifunctional, linear units) replaced a part of the Jeffamine D component of the resins (amino-H-tetrafunctional: two branching centers connected with an elastic chain). This causes a decrease of chemical crosslink density, although under favorable conditions, some Sn2 units should form physical crosslinks via $\mathrm{Sn} 2-\mathrm{Sn} 2$ interactions. The Sn2 nanofiller was chosen from among the synthetically available stannoxanes because of its especially high anti-oxidizing activity [41]. A content of $20 \mathrm{wt} \%$ Sn2 was incorporated in all the nanocomposites investigated, in order to obtain a strong nanofiller effect on one hand, while at the same time limiting the decrease of crosslinking density via Sn2 incorporation: $20 \mathrm{wt} \%$ of $\mathrm{Sn} 2$ corresponded to $10,4.8$ and 3.9 amino-H-mol\% $\mathrm{Sn} 2$ in the matrices with the D2000, D400 and D230 amino component, respectively.

The nanocomposite syntheses were performed similarly like the matrix synthesis: the appropriate amounts of liquid Jeffamine D, of supercooled liquid DGEBA and of a $50 \mathrm{wt} \%$ solution of the $\mathrm{Sn} 2$ nanofiller in toluene were mixed and stirred under argon at $120^{\circ} \mathrm{C}$ until gelation. Thereafter, the solvent was removed under vacuum, and the plastic early post-gel mixture was put into a mold (a)

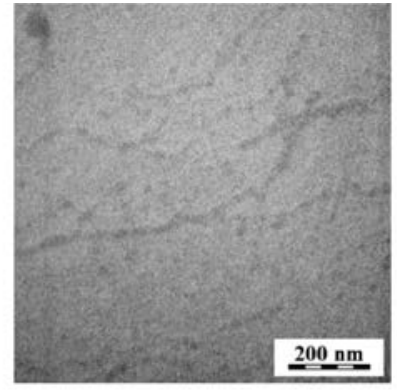

(d)

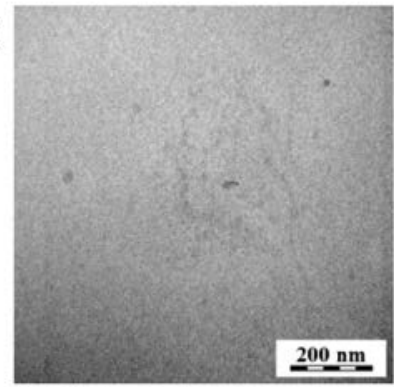

(g)

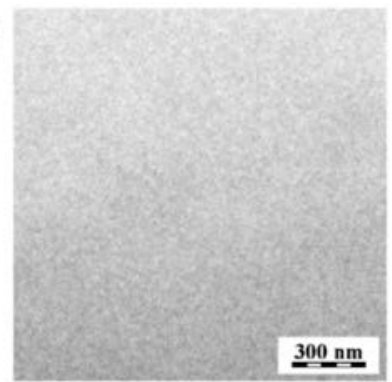

(b)

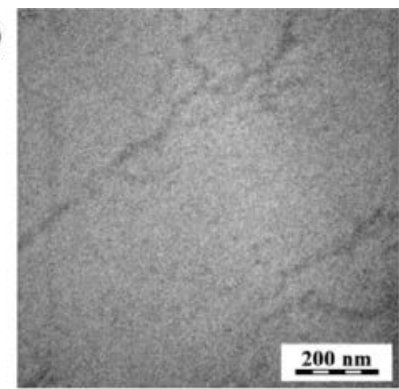

(e)

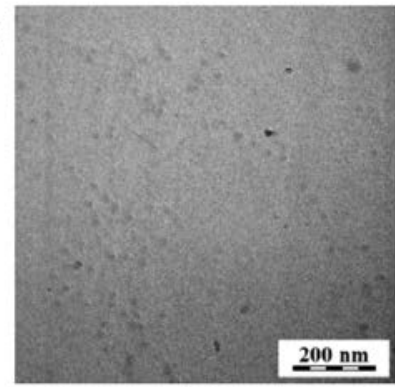

(h)

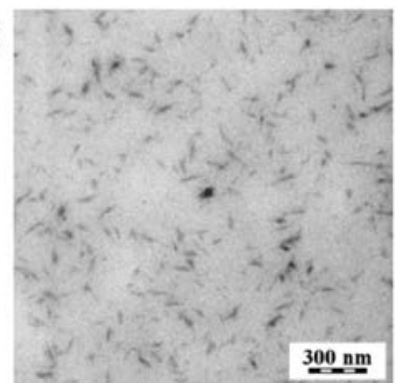

(c)

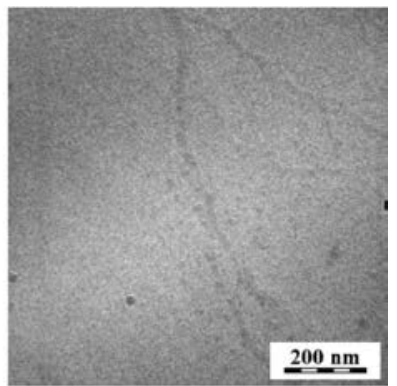

(f)

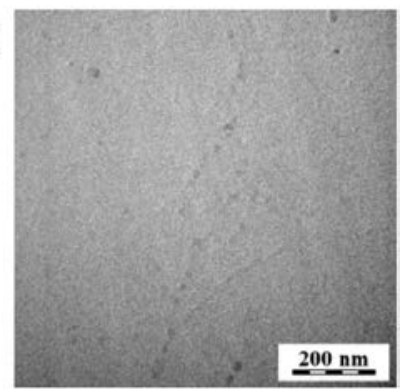

(i)

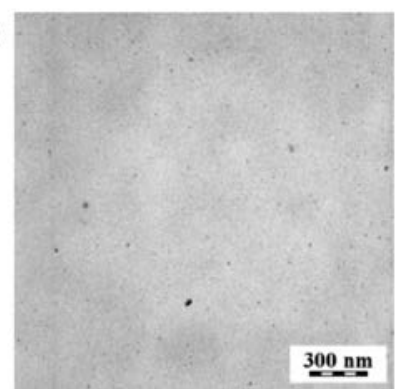

Fig. 1. Morphology of the studied nanocomposites of the inorganic Sn2 cage with the epoxy matrices DGEBA-D230 (a-c row), DGEBA-D400 (d-f) and DGEBA-D2000 (g-i); the nanocomposites were cured normally (left column: a, d, g), additionally annealed (center: b, e, h) or underwent additional oxidative treatment (right: $\mathrm{c}, \mathrm{f}, \mathrm{i}$ ). 
and cured at $120^{\circ} \mathrm{C}$ for 3 days ("standard cure"). The use of solvent was necessary in order to assure fine nanofiller dispersion.

The relative size of the nanofiller in comparison to the matrix network mesh is illustrated in Scheme 8: in the case of the elastic matrix with D2000 chains, the mesh - if fully stretched - is wide in comparison to the size of the Sn2 cage. With D400 chains, the matrix mesh is narrower, but the rigid Sn2 units just fit into it. In the case of D230 as elastic chains, the matrix mesh is distinctly smaller than the Sn2 cages, although the sizes are comparable. Sn2 incorporation hence causes a significant decrease of crosslink density in the matrix, because the formation of some crosslinks will be prevented by sterical hindrance (chains too short to close a loop around an Sn2 unit, see Scheme 9). This plastifying effect would disappear again, if the network mesh were much smaller than the filler particles (not investigated in this work, e.g. larger montmorillonite nano-platelets in thermoset networks).

The Sn2 nanocomposites with each matrix were cured via the "standard procedure" (see Experimental Part). Selected samples underwent additional annealing for 12 at $180^{\circ} \mathrm{C}$ under argon (nanofiller polymerization to larger stannoxanes), or oxidative treatment ( $12 \mathrm{~h}$ in circulating air at $180^{\circ} \mathrm{C}$ ) in order to evaluate the anti-oxidative effect of $\mathrm{Sn} 2$ (see procedures in Scheme 5). The temperature and duration of the annealing were chosen in order to achieve a high conversion in the nanofiller oligomerization reaction, while at the same time avoiding significant thermal matrix degradation, in accordance with previous investigations of stannoxane-epoxy nanocomposites [40]. The given conditions of the oxidative treatment were chosen, because after such a treatment, the most elastic among the investigated matrices degrades to a fully soluble material (fraction of gel $=0$ ).

\subsection{Morphology of the studied samples via TEM}

The effect of the network mesh size on the morphology of the epoxy-stannoxane ("Sn2") nanocomposites was investigated by means of transmission electron microscopy (TEM, see Fig. 1).

The nanocomposite of the DGEBA-D2000 matrix with the Sn 2 cage $(20 \mathrm{wt} \%)$ is highly homogeneous after the standard cure (Fig. 1g). After the annealing treatment $\left(180^{\circ} \mathrm{C}\right)$ which leads to Sn2 cages oligomerization, a distinct nano-phase separation san be observed (Fig. 1h), as result of short-range Sn2 mobility (see Scheme 10), which was first observed in a previous work of the authors [41], and which is connected with the dissociation ability of the oxonium bonds which carry the functional substituents of Sn2. A much smaller nano-phase separation is

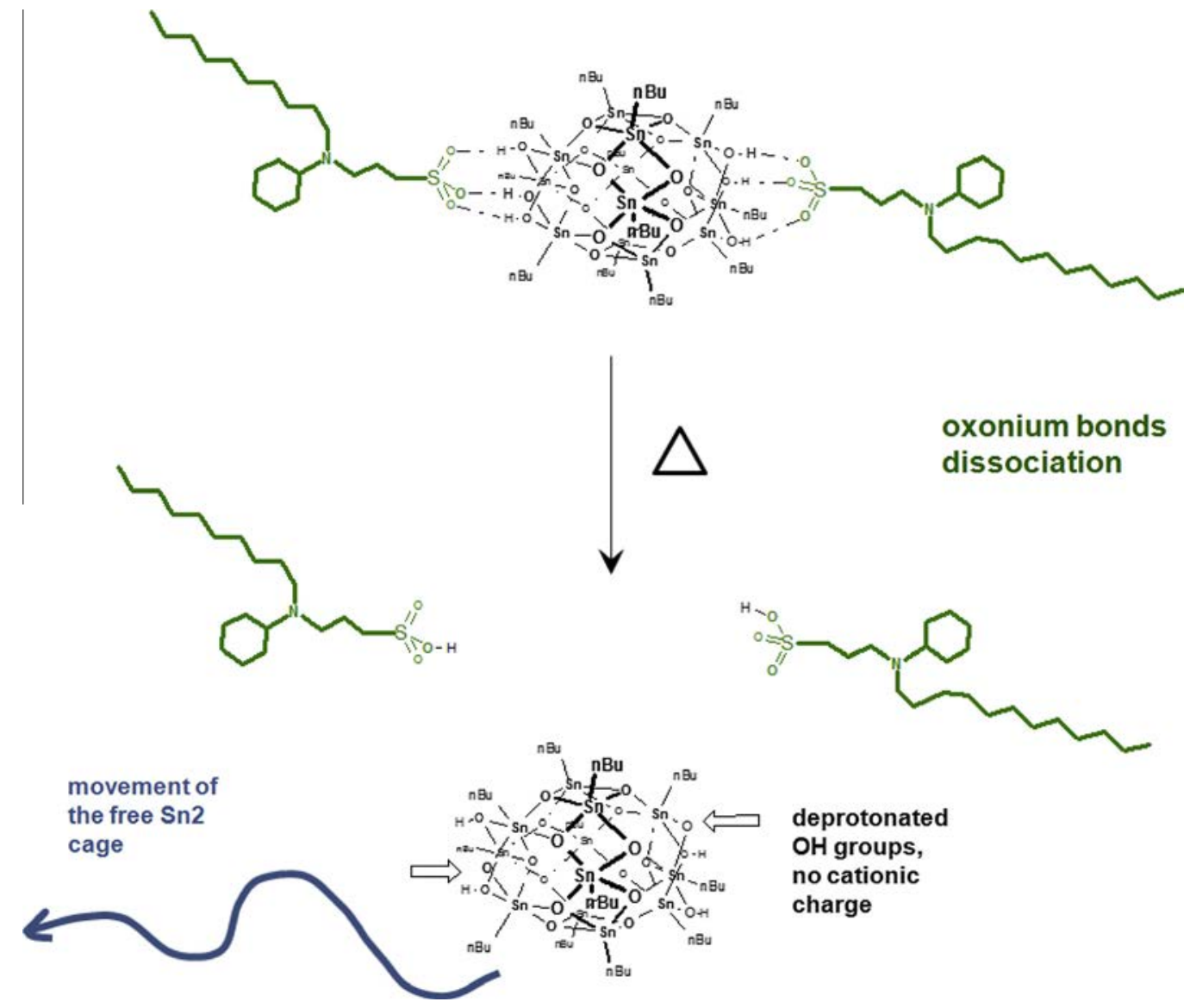

Scheme 10. Short-range mobility of the Sn2 units at elevated temperatures via dissociation of the oxonium bonds to the functional (axial) substituents and subsequent detachment from bonded positions, as described in [41]. 

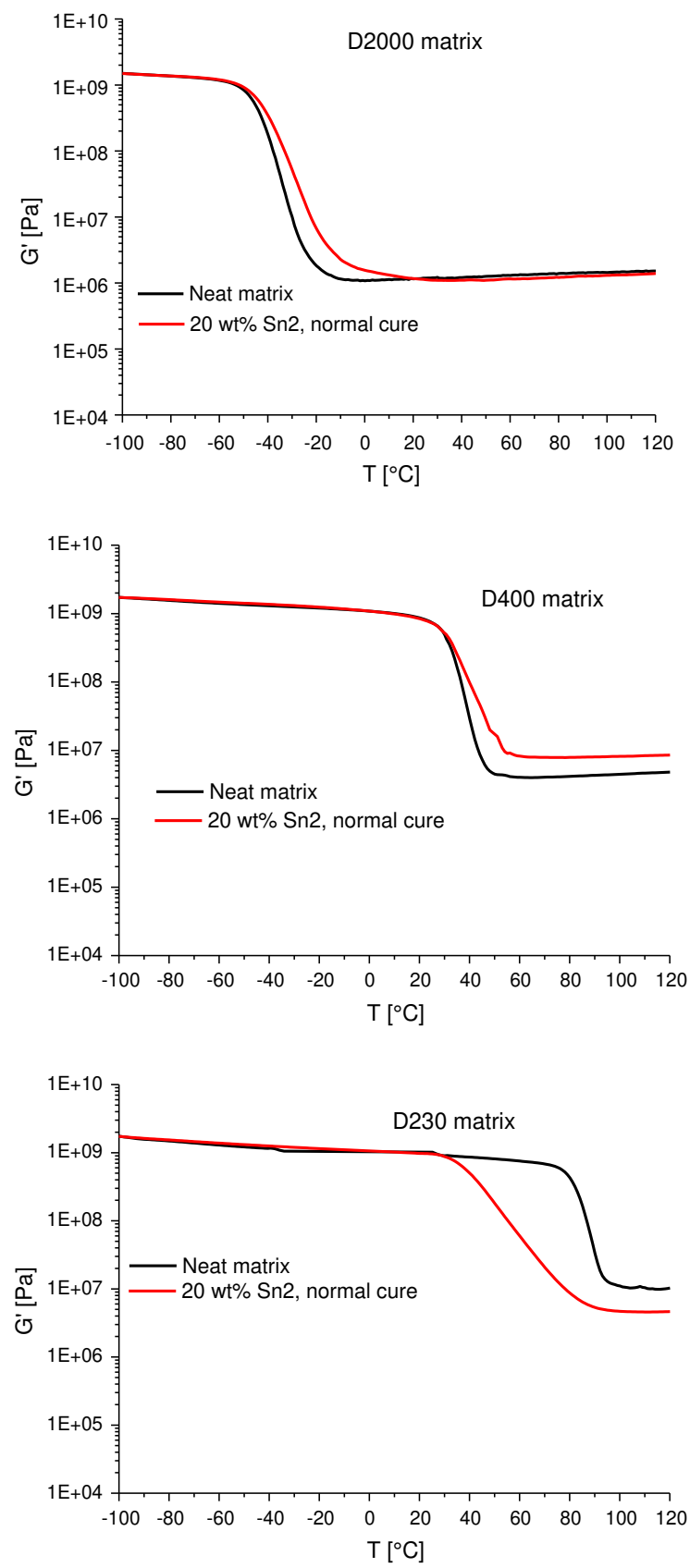

Fig. 2. Reinforcement by the Sn2 nanofiller after normal cure, D2000-, D400- and D230-based matrix (from top to bottom, respectively); shear storage modulus $G^{\prime}$ as function of temperature.

observed in the DGEBA-D2000-Sn2 nanocomposite after the oxidative treatment (Fig. 1i), obviously as result of the fixation of $\mathrm{Sn} 2$ by the oxidative cross-linking reactions (see Scheme 2) between nanofiller and matrix, as observed also in [41].

In the nanocomposite with the narrower matrix mesh, DGEBA-D400-Sn2, the morphology is practically homogeneous after the normal cure, but occasional fine nanoheterogeneities can be observed (Fig. 1d). Practically no increase of heterogeneity or a very slight one is observed
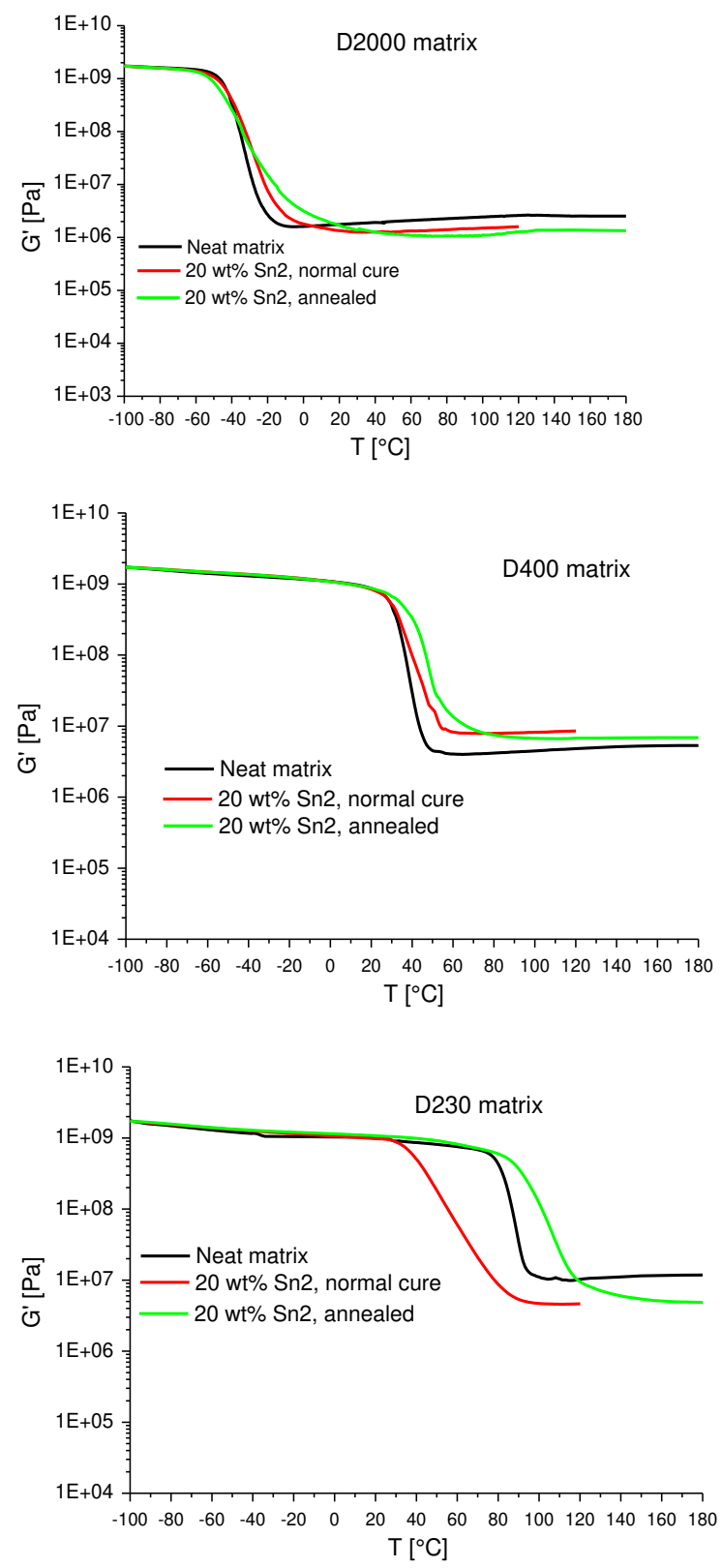

Fig. 3. Reinforcement by the Sn2 nanofiller after annealing under argon (nanofiller oligomerization), D2000-, D400- and D230-based matrix (from top to bottom, respectively); shear storage modulus $G^{\prime}$ as function of temperature.

(Fig. 1e) after the annealing (Sn2 oligomerization): the short-range mobility observed for $\mathrm{Sn} 2$ in the DGEBAD2000 matrix is obviously strongly hindered by the narrow matrix mesh, which needs to be fully extended in order for a Sn2 unit to pass through it. After the oxidative treatment, the DGEBA-D400-Sn2 nanocomposite expectedly displays a practically homogeneous morphology (Fig. 1f), due to the mentioned poor Sn2 mobility and to oxidative crosslinking reactions between $\mathrm{Sn} 2$ and the matrix, which fix $\mathrm{Sn} 2$.

The morphology of the stannoxane nanocomposite with the narrowest mesh, DGEBA-D230-Sn2, after normal cure, 

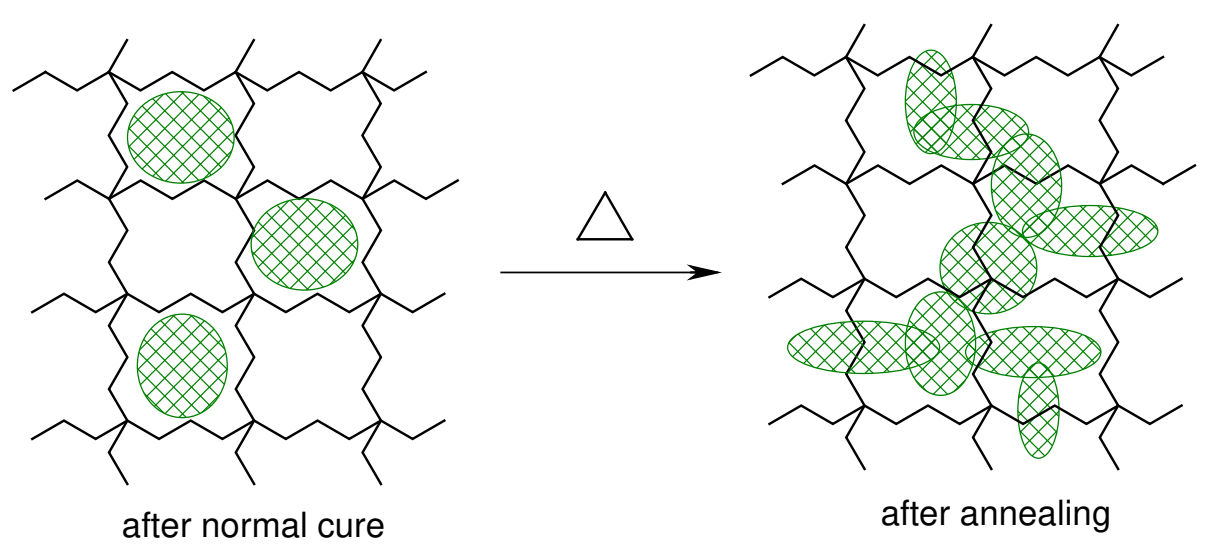

Scheme 11. Formation of branched oligomeric stannoxane structures, which interpenetrate the narrower matrix networks (e.g. DGEBA-D400, and especially DGEBA-D230).

after annealing and after oxidative treatment is shown in Fig. 1a-c. The morphology practically does not change after any additional treatment, which is obviously the result of the Sn2 nano-building blocks' efficient immobilization by the surrounding rigid, narrow-mesh matrix. The nanocomposite shows a fine but distinct nano-heterogeneity, which seems to be the result of a decreased Sn2 miscibility with the narrow mesh matrix (the loops of the network cannot close around the large Sn2 cages), which leads to the observed nano-precipitation in the later stages of this nanocomposite's synthesis.

\subsection{Thermo-mechanical-properties}

The effect of the same stannoxane Sn2 nanofiller in the epoxy matrices of different mesh width was studied via dynamic mechanical thermal analysis (DMTA) of the nanocomposites after normal cure, after annealing and after the oxidative treatment. The ratio network mesh size: Sn2 cage size was found to have a very strong influence on the nanofiller effect in the matrices.

\subsubsection{Reinforcement by the nanofiller after normal cure}

After the normal cure, the Sn2 cages are expected to reinforce the epoxy matrices via $\mathrm{Sn} 2-\mathrm{Sn} 2$ interactions (physical crosslinking). The reinforcing effect was assessed via dynamic-mechanical thermal analysis (DMTA), from the temperature dependence of the storage shear modulus $\left(G^{\prime}=f(T)\right.$ curves, see Fig. 2).

In the case of the elastomeric DGEBA-D2000 matrix with a very wide network mesh, only the glass transition temperature $\left(T_{g}\right)$ is shifted to a moderately higher value, but the modulus in the rubber region remains practically unchanged. This finding implies, that the Sn2-Sn2 interactions play a small role in the composite DGEBAD2000-(20 wt\%) Sn2, while the reinforcing effect of Sn2 consists mainly in the immobilization (via topological constraint) of the matrix in the neighborhood of the $\mathrm{Sn} 2$ cages.

In the case of the DGEBA-D400 matrix with the network mesh only slightly wider than the Sn2 cage size, an increase in the modulus in the rubber region is clearly observed, besides a moderate increase in $T_{g}$. The modulus increase can be assigned to more frequent $\mathrm{Sn} 2-\mathrm{Sn} 2$ interactions, which can be correlated with the fine and small heterogeneities observed by (TEM), while the $T_{g}$ increase is given by the immobilization (topological constraint) of elastic chains surrounding $\operatorname{Sn} 2$.

The DGEBA-D230 matrix possesses a very narrow mesh width, which is distinctly smaller, but comparable to the Sn2 nanofiller size. In the DGEBA-D230-Sn2 nanocomposite, a marked plastification of the thermoset network by the rigid nanofiller is observed, due to the sterical hindrance posed by the rigid Sn2 to the formation of network loops (and hence crosslinks) around the Sn2 cages (see Scheme 9). This yields a matrix network with a lower crosslink density and hence with a significantly lower modulus in the rubber region. The looser, defect network structure consequently displays a markedly lower $T_{g}$ (decrease by nearly $30^{\circ} \mathrm{C}$ ), due to easier relaxation. The DGEBA-Jeffamine D matrix resins behave like copolymers with mutually fully miscible components and display only one glass transition for the whole structure. The observed $T_{g}$ value results from the immobilization of the flexible Jeffamine $D$ segments by the rather rigid DGEBA-NDGEBA-N-chains (see structure in Scheme 6), which are connected to them. Especially in the case of the short D230 elastic chains, the crosslinks which failed to connect make the whole matrix structure much more flexible.

\subsubsection{Reinforcement by the nanofiller after nanofiller oligomerization (via annealing)}

The effect of the anaerobic annealing at $180^{\circ} \mathrm{C}$, which causes the oligomerization (Scheme 3) of the Sn2 nanofiller, on the thermo-mechanical properties of the investigated nanocomposites is illustrated in Fig. 3. A very strong matrix immobilization $\left(T_{g}\right.$ increase) was observed in case of the nanocomposite with the narrowest mesh.

In the case of the nanosomposite with the widest matrix mesh, DGEBA-D2000-(20 wt\%) Sn2, the effect of the Sn2 cages oligomerization on the thermo-mechanical properties is small, in contrast to the observed change in morphology (see above Fig. 1h). A moderate increase of $T_{g}$ is observed and the glass transition becomes more gradual. The shift in $T_{g}$ can be explained by the formation of larger stannoxane structures, which more efficiently immobilize the matrix. A moderate decrease in the 

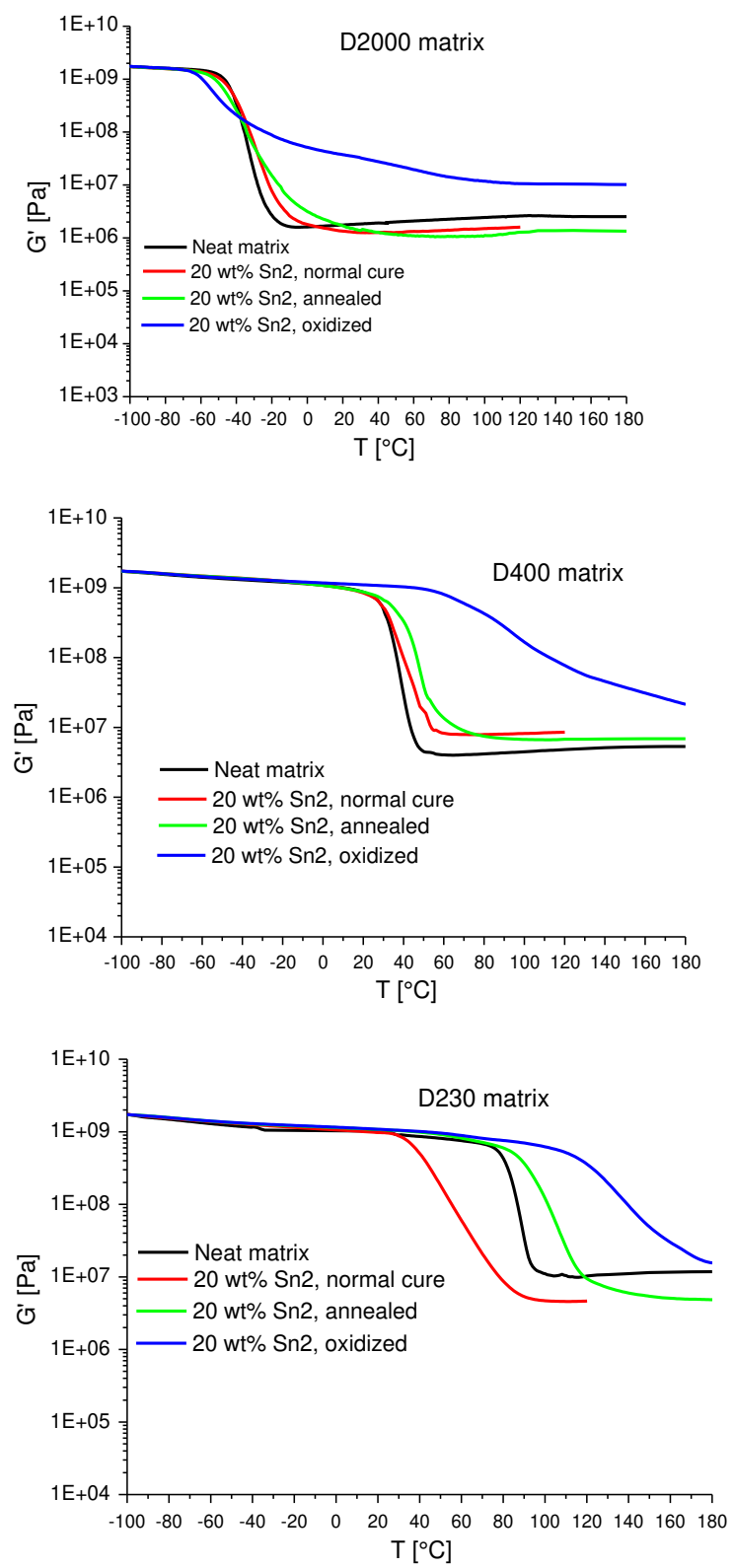

Fig. 4. Reinforcement by the $\mathrm{Sn} 2$ nanofiller after the oxidative treatment, D2000-, D400- and D230-based matrix (from top to bottom, respectively); shear storage modulus $G^{\prime}$ as function of temperature. modulus in the rubber region is also observed, and can be explained by thermal matrix degradation, which is not fully compensated by the nanofiller oligomerization: the relatively large stannoxane nano-domains (around $15 \times 80 \mathrm{~nm}$, see Fig. $1 \mathrm{~h}$ ) formed by the Sn2 nano-phase separation ( $\mathrm{Sn} 2$ mobility at high $T$ : see Scheme 10) and subsequent oligomerization necessarily lose some of the functional substituents, by which the Sn2 units were originally anchored in the matrix.

In the nanocomposite DGEBA-D400-(20 wt\%) Sn2, the effect of the nanofiller polymerization is stronger than in the wide-mesh matrix: the glass transition temperature is shifted to upwards by $7^{\circ} \mathrm{C}$ and the glass transition remains steep, while the decrease of modulus due to thermal degradation is only slight. Only small oligomeric Sn2 domains are formed after the annealing as can be seen in Fig. 1e, as the mobility of $\mathrm{Sn} 2$ is hindered by the relatively narrow network mesh. The stronger effect of $S n 2$ polymerization on the glass transition is given by the narrow mesh of the DGEBA-D400 matrix, so that the larger stannoxane domains more efficiently immobilize neighboring parts of the matrix (see Scheme 11).

In the case of the narrowest matrix mesh, with D230 elastic chains, the effect of the $\mathrm{Sn} 2$ polymerization is very strong: $T_{g}$ is shifted upwards by nearly $50^{\circ} \mathrm{C}$, the matrix which was previously plastified by the nanofiller after normal cure, is markedly reinforced ( $T_{g}$ shift) after the annealing. The moderate decrease of the modulus in the rubber region persists, however. The very strong immobilizing effect of the polymerized $\mathrm{Sn} 2$ can be explained by the strong fixation of the $\mathrm{Sn} 2$ units in the narrow network. After the Sn2 polymerization, the Sn2 cages, which were able to merge to larger structures, become part of a rigid inorganic structure which interpenetrates the matrix network and thus immobilizes it very strongly (see Scheme 11). Due to the rigidity of the narrow-mesh network, the immobilizing effect of the inorganic phase can affect also more distant segments of the inorganic matrix.

\subsubsection{Reinforcement by the nanofiller after the oxidative treatment}

The oxidative crosslinking reactions between the epoxy matrix and the stannoxane "Sn2" cages have a very strong effect on the thermo-mechanical properties of the studied nanocomposites (Fig. 4): instead of mechanical properties degradation, the DGEBA-Jeffamine-Sn2 nanocomposites become additionally reinforced via the mentioned cross-

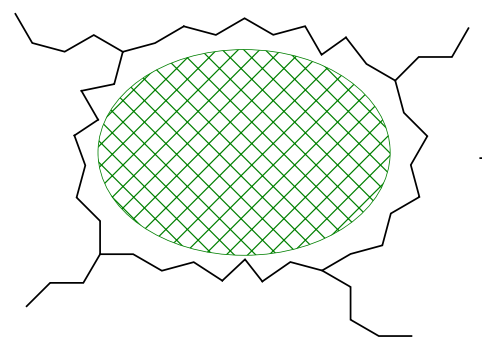

after normal cure

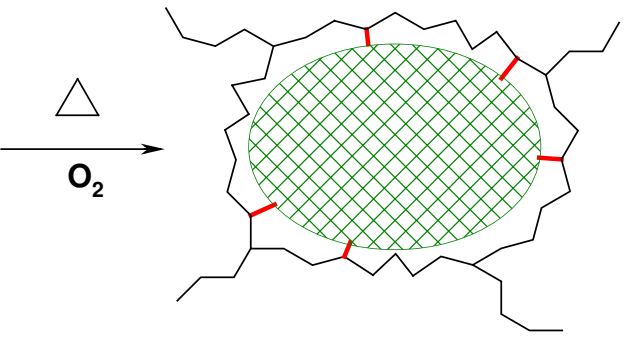

after oxidative treatment

Scheme 12. Attachment via oxidative crosslinking of the Sn2 cage to the DGEBA-D400 matrix network, which closely surrounds it: an immobilizing effect is achieved, but the crosslinking has no effect on modulus, as the stretched elastic chains "enveloping" the Sn 2 cage were not elastically active previously. 
linking reactions. Two effects can be observed from the $G^{\prime}=f(T)$ curves in Fig. 4: the increase of the modulus in the rubber plateau, which is most marked with the widest matrix mesh, and the increase of the glass transition temperature $\left(T_{g}\right)$, which is the highest in case of the narrowest mesh.

The DGEBA-D2000-(20 wt\%) Sn2 nanocomposite does possess the widest network mesh, and also contains the longest polypropylene oxide sequences (34-mer), in which the ternary $>\mathrm{CH}-(\mathrm{O}-)$ units display a high ability to undergo radical reactions. The phenyl rings an methyl groups of DGEBA, on the other hand, are unreactive. Consequently, the oxidative crosslinking between the DGEBAD2000 matrix and Sn2 is very efficient in this system, and the modulus in the rubber region rises by nearly one order of magnitude. The glass transition becomes much broader after the oxidative treatment, which is caused by oxidative damage to the structure regularity (transition onset at lower temperature) in combination with elastic chains immobilization via new bonds to Sn2 (extension of the transition to higher temperatures).

In the case of the DGEBA-D400-(20 wt\%) Sn2 nanocomposite, the oxidative treatment causes a very strong shift of $T_{g}$ to higher temperatures, by $60-70^{\circ} \mathrm{C}$, while the real increase in equilibrium modulus in the rubbery state, which can be estimated from Fig. 4, remains only moderate. This finding can be explained by less efficient crosslinking between the polypropylene oxide chains, which are much shorter than in case of D2000 (7 vs. 34 repeat units), and Sn2. Additionally, the Sn2 cage just fits into the network mesh. The single Sn2 units or Sn2 oligomers are hence typically attached to the stretched D400 chains which encircle them (Scheme 12). Thus the immobilization of the matrix is highly increased, but the new crosslinks have little effect on the elasticity of the nanocomposite, because the chains newly bonded to Sn2 have not been elastically active previously. The more distant D400 chains, which were previously not immobilized, and which - for sterical reasons - have little possibility to come close to the $\mathrm{Sn} 2$ units, are seldom involved in matrix-Sn2 crosslinking. In this way, the immobilizing effect on the matrix is much more prominent than the increase of the effective crosslink density in the case of the DGEBA-D400 matrix.

An interesting result is obtained for the DGEBA-D230(20 wt\%) Sn2 nanocomposite: the oxidative treatment leads to a tremendous increase of the glass transition temperature in comparison with the normally cured DGEBAD230-Sn2, by approximately $90^{\circ} \mathrm{C}$. In contrast to the nanocomposite with the D400 chains, a significant increase in crosslinking density in the rubber region can be estimated for the oxidized DGEBA-D230-Sn2 sample from Fig. 4.

Analogous trends can be expected for the effect of Sn2 after the oxidative treatment in the DGEBA-D230 matrix, like in the one with D400 chains. An important difference is however, that the narrow matrix mesh with D230 chains is damaged by the $\mathrm{Sn} 2$ incorporation during normal cure, which leads to the above discussed matrix plastification (Fig. 2). Some loops of the network mesh are not closed because of the size of Sn2, and D230 chains, which would otherwise be elastically active, are incorporated only as dangling chains (Scheme 9). Importantly, these dangling
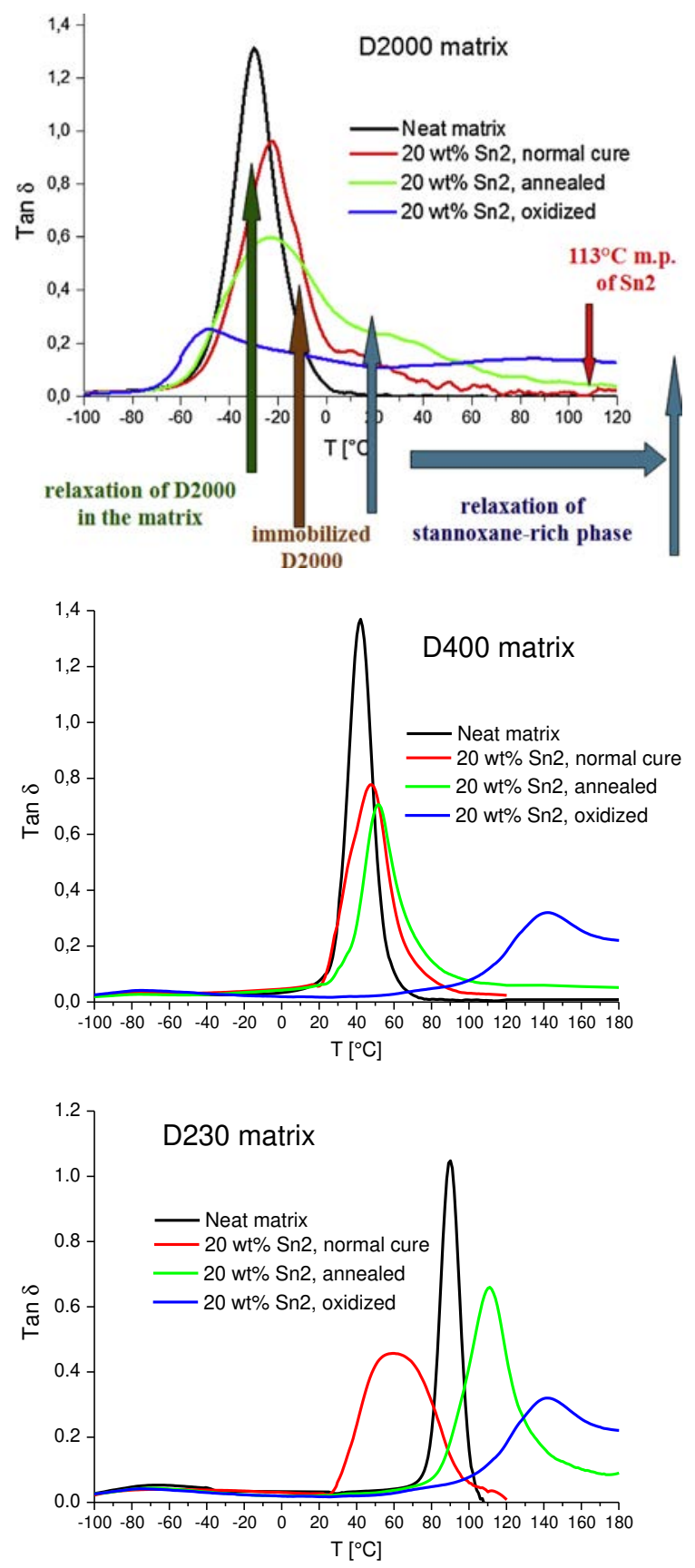

Fig. 5. Assignment of the thermo-mechanical transitions in the epoxySn2 nanocomposites after normal cure, annealing, and oxidation: D2000-, D400- and D230-based matrix (from top to bottom, respectively); loss factor $\tan (\delta)$ as function of temperature.

D230 chains are always in the neighborhood of Sn2 units, and their attachment to Sn2 via oxidative radical reactions increases the effective crosslinking density of the matrix, thus compensating for the originally reduced crosslinking. This effect was absent with D400, as the D400 chains neighboring with $\mathrm{Sn} 2$ were not involved in any defects (Scheme 12). 

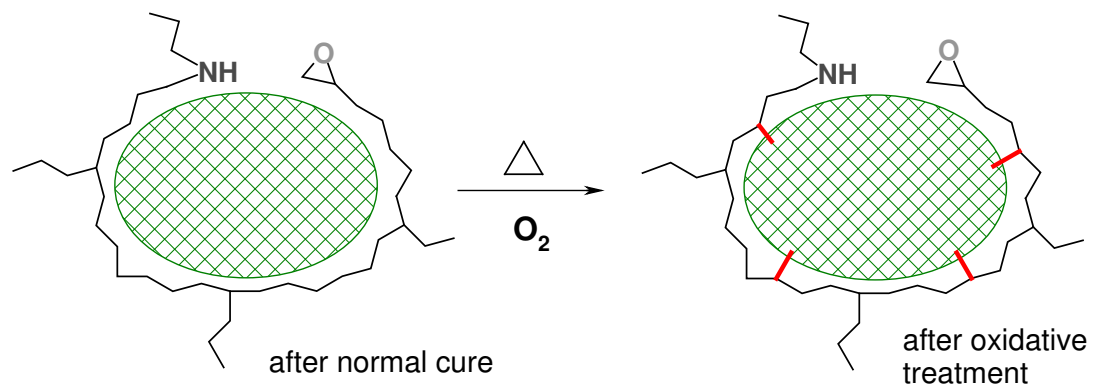

Scheme 13. Attachment via oxidative crosslinking of the Sn2 cage to the DGEBA-D230 matrix network, which closely surrounds it: an immobilixing effect is achieved, as well as a significant increase in crosslinking: the dangling chains from incomplete network loops which are "enveloping" the Sn2 cage become attached and the overall crosslink density increases.

\subsubsection{Assignment of the thermal phase transitions}

The effect of the stannoxane Sn2 cages on the thermomechanical properties of the studied nanocomposites can be further evaluated by analyzing the thermal phase transitions, which can be assigned from the $\tan (\delta)=f(T)$ curves shown in Fig. 5. The neat DGEBA-Jeffamine D matrices behave like a co-polymers with mutually fully miscible phases and display only one glass transition. The glass transition temperature is determined by the immobilization of the mobile and elastic polypropylene oxide (Jeffamine) chains by the more rigid DGEBA$\mathrm{N}$-DGEBA-N-chains, to which the Jeffamine chains are connected (see structure in Scheme 6). The DGEBAJeffamine-Sn2 nanocomposites behave like copolymers with mutually immiscible components, DGEBA-Jeffamine D, and the Sn2-rich phase.

Three types of relaxations can be observed in these nanocomposites (see assignment in Fig. 5): unhindered relaxation of the matrix (mainly the Jeffamine $D$ chains), relaxation of topologically constrained matrix chains in the neighborhood of the nanofiller, which is shifted to slightly higher temperatures, and finally, the relaxation of a stannoxane-rich phase, which is typically observed only at higher stannoxane contents $[40,41]$. The phase transitions in the three matrices studied, with a wide, narrow and very narrow mesh show distinctly different trends.

The nanocomposite DGEBA-D2000-(20 wt\%) Sn2 with the very wide mesh is the only one among the investigated systems, in which the glass transition of a stannoxane-rich phase can be observed. This is especially the case after annealing under argon (during which relatively large stannoxane-rich nano-domains form) and after the oxidative crosslinking (which also leads to the formation of small Sn2-rich nano-domains). After standard cure, only a small broad peak can be observed for the Sn-rich phase (which has little prominence). The glass transition of the sterically immobilized matrix is also much less prominent than the unhindered DGEBA-D2000 relaxation.

In the case of the nanocomposite with the narrower mesh, DGEBA-D400-(20 wt\%) Sn2, the transition of the Sn2-rich phase is not observed (although it might be eventually covered by the other peaks). After normal cure, the transition of the immobilized fraction of the DGEBA-D400 matrix is more prominent than the unhindered matrix relaxation, which seems to be the consequence of the relatively tight contact with the embedded $\mathrm{Sn} 2$, as well as of a higher matrix rigidity. After the annealing ( $\mathrm{Sn} 2$ oligomerization), only a narrow transition of the immobilized matrix is observed (no unhindered matrix relaxation), which indicates the enhancement of the previous immobilization through the merger of neighboring $\mathrm{Sn} 2$ units to larger structures tightly enveloped by the matrix (Scheme 11). The immobilizing effect then spans across the entire matrix. The oxidative treatment leads again to only one transition, although a broadened one, at much higher temperatures. The broadening is most probably the consequence of irregularities caused by the oxidation, while the $T_{g}$ shift is the result of a much increased segmental immobilization of the matrix via the attachment of the neighboring elastic chains to Sn2 (Scheme 12).

In the case of the nanocomposite with the narrowest mesh, DGEBA-D230-(20 wt\%) Sn2, the trends in thermomechanical transitions are similar to the ones with the DGEBA-D400 matrix, but with some distinct differences: after normal cure, only one glass transition is observed, but it is shifted $30^{\circ} \mathrm{C}$ to lower temperatures in comparison to the neat matrix, and it is much broader. This change is a consequence of the structural defects caused by the size of the Sn2 nanofiller relatively to the matrix mesh: numerous crosslinks do not form (Scheme 9), the matrix is looser, less regular and contains dangling chains (broader transition). After the annealing, the formation of interpenetrating $\mathrm{Sn} 2$ oligomers very strongly immobilizes the matrix, much more than in the case of D400 chains, and the glass transition somewhat narrows (smaller effect of the dangling chains in the new structure). The oxidative treatment leads to a very strong shift of the transition to higher temperatures, similarly like in case of D400, due to efficient matrix attachment to Sn2 via oxidative cross-linking (Scheme 13).

\section{Conclusions}

- Nanocomposites of the amino-functional, linearly bonding inorganic butylstannoxane cage "Sn2" with epoxy matrices displaying different mesh sizes were successfully prepared.

- The nanocomposites mostly display a homogeneous morphology (TEM). With the long elastic D2000 chains, where the segmental mobility of the nanofiller is unrestricted, nano-phase separation is observed after 
annealing at $180^{\circ} \mathrm{C}$, and to a smaller extent, also after oxidative treatment at $180^{\circ} \mathrm{C}$. With the very short D230 elastic chains, a fine heterogeneity is observed in the nanocomposites, which does not change after any additional treatment. This nano-phase separation during nanocomposite synthesis is obviously due to the difficult incorporation of the large nanofiller into the narrow matrix network.

- After normal cure, the stannoxane nanofiler efficiently reinforces the epoxy matrices with a wider mesh, in which it fits without problems.

- The matrix with the narrow mesh (D230 chains) is plastified by the nanofiller incorporation, as the latter sterically hiders the connection of some crosslinks.

- The thermal polymerization of the nanofiller units, which is achieved by anaerobic nanocomposite annealing at $180^{\circ} \mathrm{C}$, reinforces all the nanocomposites. The change is most marked in the network with the narrowest mesh, where the polymerized inorganic phase obviously is forced to interpenetrate the narrow network, thus causing a further reinforcement in addition to the simple merger of the chemically bonded nanofiller units.

- The oxidative treatment shows, that the stannoxane nanofiller causes an efficient matrix stabilization against oxidative degradation, via oxidative crosslinking reactions stannoxane-matrix. The effect is strong in all the investigated matrices: the increase in the glass transition temperature is maximal with the narrowest mesh, where the flexibility of the network structure is most strongly affected by the large nanofiller, while the increase in the "rubber modulus" is highest with the widest mesh, where most numerous crosslinking sites can be found on the long elastic chains of the matrix. The rubber modulus also increases in the matrix with the narrowest mesh, in which the oxidative crosslinking reactions compensate for previous structural defects caused by the too large nanofiller. In case of matrix mesh width comparable with the nanofiller size, only the glass transition temperature is shifted strongly upwards, but no increase of modulus is observed, as the oxidative crosslinks are mostly formed to matrix segments which were already immobilized sterically by the filler.

\section{Acknowledgements}

The authors thank Ms. Jiřina Hromádková (electron microscopy).

The authors thank the Czech Science Foundation Czech Republic, Grant Nr. 108/11/2151 for the financial support of this work.

\section{References}

[1] Hakimelahi HR, Hu L, Rupp BB, Coleman MR. Polymer 2010;51: 2494-502.
[2] Durmus A, Ercan N, Soyubol G, Deligoz H, Kasgoz A. Polym Compos 2010;31:1056-66.

[3] Spirkova M, Brus J, Hlavata D, Kamisova H, Matejka L, Strachota A Surf Coat Int Part B - Coat Trans 2003;86:187-93.

[4] Zhou Weidong, Yu Yingchao, Chen Hao, DiSalvo FJ, Abruna HD. J Am Chem Soc 2013;135:16736-43.

[5] Matteucci S, Van Wagner E, Freeman BD, Swinnea S, Sakaguchi T, Masuda T. Macromolecules 2007;40:3337-47.

[6] Weng CJ, Huang JY, Huang KY, Jhuo YS, Tsai MH, Yeh JM. Electrochim Acta 2010;55:8430-8.

[7] Lin Z, Cheng YR, Lu H, Zhang LA, Yang B. Polymer 2010:51:5424-31.

[8] Miniewicz A, Girones J, Karpinski P, Mossety-Leszczak B, Galina H, Dutkiewicz M. J Mater Chem C 2014;2:432-40.

[9] Rao YQ, Chen S. Macromolecules 2008;41:4838-44.

[10] Hu GJ, Zhao CG, Zhang SM, Yang MS, Wang ZG. Polymer 2006;47: 480-8.

[11] Kim H, Abdala AA, Macosko CW. Macromolecules 2010;43:6515-30.

[12] Robbes AS, Jestin J, Meneau F, Dalmas F, Sandre O, Perez J, et al. Macromolecules 2010;43:5785-96.

[13] Horak D, Trchova M, Benes MJ, Veverka M, Pollert E. Polymer 2010;51:3116-22.

[14] Wu JR, Huang GS, Li H, Wu SD, Liu YF, Zheng J. Polymer 2013;54: 1930-7.

[15] Maji PK, Das NK, Bhowmick AK. Polymer 2010;51:1100-10.

[16] Spirkova M, Strachota A, Urbanova M, Baldrian J, Brus J, Slouf M, et al. Mater Manuf Processes 2009;24:1185-9.

[17] Spirkova M, Brus J, Brozova L, Strachota A, Baldrian J, Urbanova M, et al. Prog Org Coat 2008;61:145-55.

[18] Dal Pont K, Gérard J-F, Espuche E. J Polym Sci, Part B: Polym Phys 2013;51:1051-9.

[19] Gao J, Bai HW, Zhou X, Yang GH, Xu CL, Zhang Q, et al. Nanotechnology 2014;25:025702.

[20] Fukumaru T, Fujigaya T, Nakashima N. Macromolecules 2013;46: 4034-40.

[21] Yu JC, Tonpheng B, Grobner G, Andersson O. Macromolecules 2012; 45:2841-9.

[22] Milliman HW, Ishida H, Schiraldi DA. Macromolecules 2012 . 45:4650-7.

[23] Spirkova M, Strachota A, Strachotova B, Urbanova M. Surf Eng 2008;24:268-71.

[24] Matějka L, Strachota A, Pleštil J, Whelan P, Steinhart M, Šlouf M. Macromolecules 2004;37:9449-56.

[25] Strachota A, Kroutilová I, Kovářová J, Matějka L. Macromolecules 2004;37:9457-64.

[26] Strachota A, Whelan P, Kř́rž J, Brus J, Urbanová M, Šlouf M, et al. Polymer 2007:48:3041-58.

[27] Brus J, Urbanova M, Strachota A. Macromolecules 2008;41:372-86.

[28] Eychenne-Baron C, Ribot F, Steunou N, Sanchez C. Organometallics 2000;19:1940-9.

[29] Ribot F, Escax V, Martins JC, Biesemans M, Ghys L, Verbruggen I, et al. Chem - A Eur J 2004;10:1747-51.

[30] Van Lokeren L, Willem R, van der Beek D, Davidson P, Morris GA, Ribot F. J Phys Chem C 2010;114:16087-91.

[31] Puff H, Reuter H. J Organomet Chem 1989;373:173-8.

[32] Dakternieks D, Zhu H, Tiekink ERT, Colton RJ. J Organomet Chem 1994;476:33-8.

[33] Chandrasekhar V, Gopal K, Singh P, Narayanan RS, Duthie A. Organometallics 2009;28:4593-601.

[34] Holmes RR. Acc Chem Res 1989;22:190-4.

[35] Ribot F. In: Davies AG, Gielen M, Pannell KH, Tiekink ERT, editors. Tin chemistry: fundamentals, frontiers, and applications. Chichester (UK): Wiley; 2008. p. 69-92.

[36] Eychenne-Baron C, Ribot F, Steunou N, Sanchez C. J Organomet Chem 1998;567:137-42.

[37] Ribot F, Banse F, Diter F, Sanchez C. New J Chem 1995;19:1145-53.

[38] Ribot F, Lafuma A, Eychenne-Baron C, Sanchez C. Adv Mater 2002;14:1496-9.

[39] Ribot F, Veautier D, Guillaudeu SJ, Lalot T. J Mater Chem 2005;15: 3973-8.

[40] Strachota A, Ribot F, Matějka L, Whelan P, Starovoytova L, Plestil J, et al. Macromolecules 2012;45:221-37.

[41] Strachota A, Rodzen K, Ribot F, Perchacz M, Trchová M, Steinhart M, Starovoytova L, Slouf M, Strachota B. Polymer, accepted for publication. 